\title{
Multiple Brain Infarction Associated with Cholesterol Embolization Syndrome
}

Michitaka Maekawa, Nozomi Sugino, Kenshi Watanabe and Rie Nomura

Key words: cholesterol embolism, cerebral infarction, atheromatous embolization

(Intern Med 56: 2531-2533, 2017)

(DOI: 10.2169/internalmedicine.8733-16)
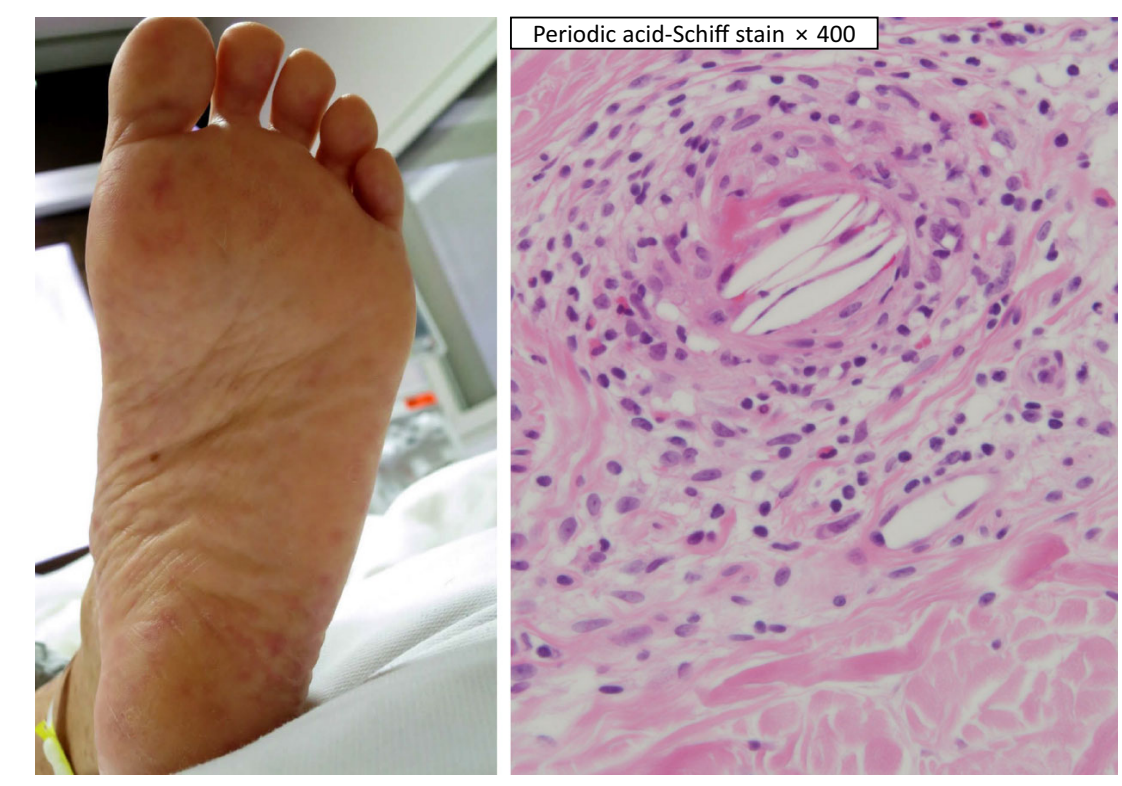

Picture 1.
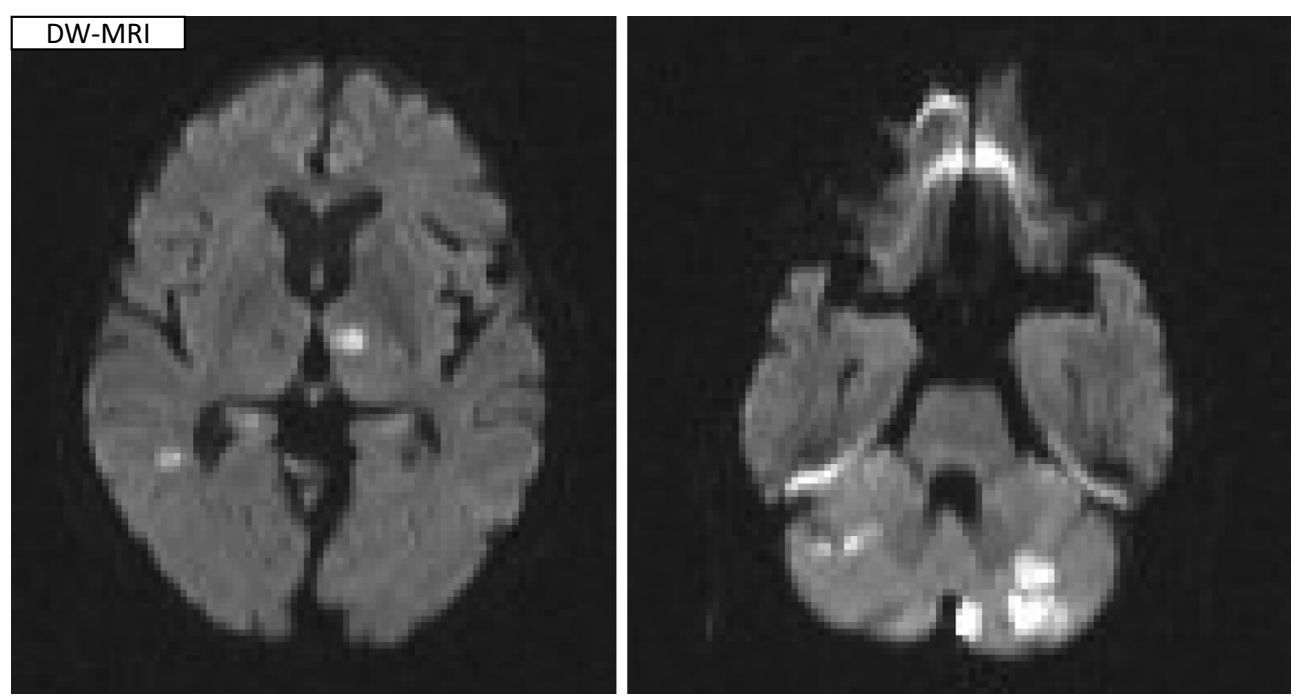

Picture 2.

Department of Nephrology, Toyohashi Municipal Hospital, Japan

Received: December 19, 2016; Accepted: January 24, 2017; Advance Publication by J-STAGE: August 21, 2017

Correspondence to Dr. Michitaka Maekawa, maekawa-michitaka@toyohashi-mh.jp 


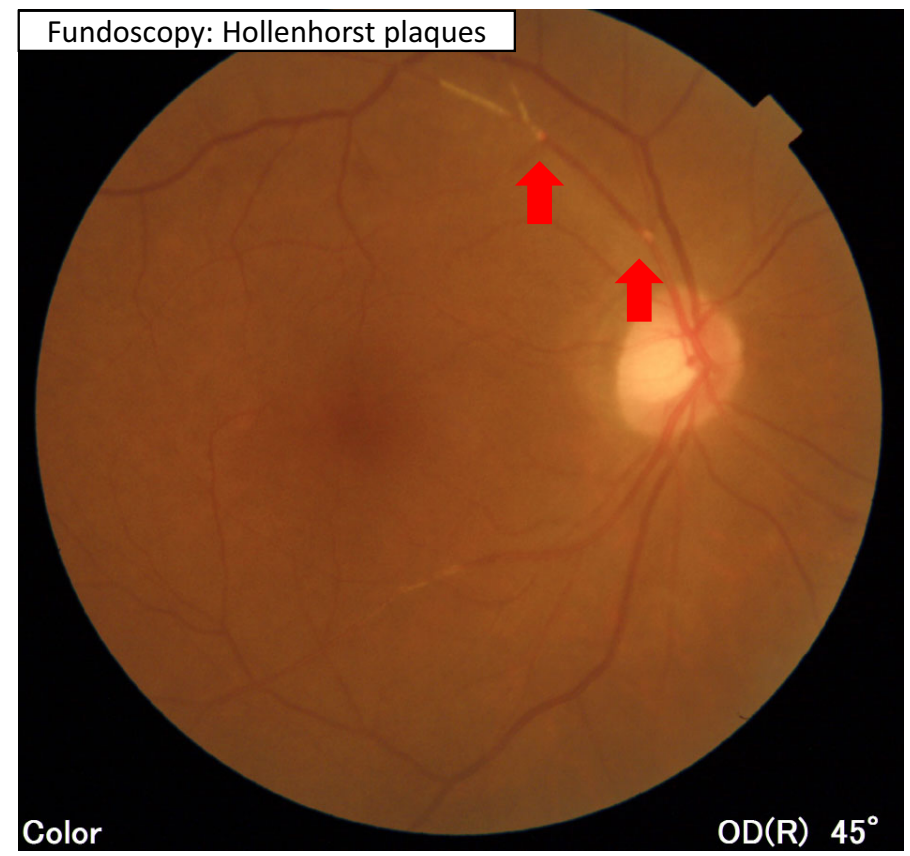

Picture 3.
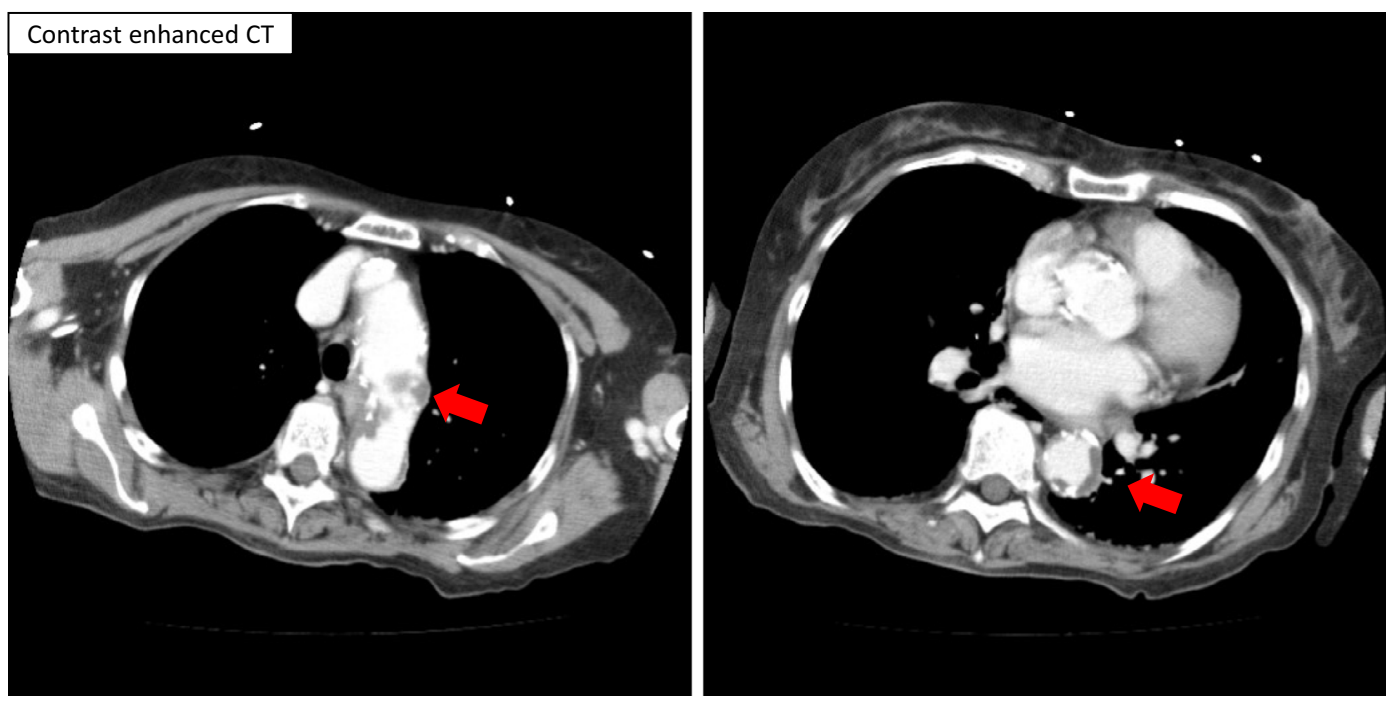

Picture 4.

A 72-year-old woman who was a hemodialysis patient presented with an impaired mental status several days after undergoing coronary angioplasty for angina pectoris. Livedo reticularis was noted on both feet (Picture 1). Magnetic resonance imaging showed acute multiple brain infarctions in the bilateral cerebral hemispheres and cerebellum (Picture 2). The cutaneous and funduscopic features combined with the imaging findings led to a diagnosis of cholesterol embolization syndrome with neurological involvement (Picture 3). The patient's urine output on admission was $<100$ $\mathrm{mL} /$ day. A complete recovery from her neurological symptoms and an increased urine volume were observed after 4 weeks of corticosteroid therapy.

The clinical manifestations of cholesterol embolization syndrome consist of signs and symptoms related to end- organ damage and systemic inflammation. The involvement of the central nervous system is reflected by an altered mental status, transient ischemic attack, or focal neurological deficits (1). A definitive diagnosis can only be made when cholesterol crystals are demonstrated in the occluded arterioles; thus, protruding aortic atheroma (as illustrated in Picture 4) and other clinical signs should also be considered when diagnosing neurological embolization (1). Since it is possible that anticoagulation therapy may worsen atheromatous embolization (2), accurately differentiating the pathology from cardiogenic embolism is of critical importance.

The authors state that they have no Conflict of Interest (COI). 


\section{References}

1. Scolari F, Ravani P. Atheroembolic renal disease. Lancet 375: 1650-1660, 2010.

2. Kronzon I, Saric M. Cholesterol embolization syndrome. Circula- tion 122: 631-641, 2010

The Internal Medicine is an Open Access article distributed under the Creative Commons Attribution-NonCommercial-NoDerivatives 4.0 International License. To view the details of this license, please visit (https://creativecommons.org/licenses/ by-nc-nd/4.0/).

(C) 2017 The Japanese Society of Internal Medicine Intern Med 56: 2531-2533, 2017 